\title{
Heritability estimates derived from threshold analyses for reproduction and stayability traits in a beef cattle herd
}

\author{
R.R. van der Westhuizen ${ }^{1}$, S.J. Schoeman ${ }^{1 \#}$, G.F. Jordaan ${ }^{1}$ and J.B. van Wyk ${ }^{2}$ \\ ${ }^{1}$ Department of Animal Science, University of Stellenbosch, Private Bag X1, Matieland 7602, South Africa \\ ${ }^{2}$ Department of Animal Science, University of the Orange Free State, P.O. Box 339, Bloemfontein 9300, South Africa.
}

\begin{abstract}
The object of this study was to estimate heritabilities and sire breeding values for stayability and reproductive traits in a composite multibreed beef cattle herd using a threshold model. A GFCAT set of programmes was used to analyse reproductive data. Heritabilities and product-moment correlations between predicted breeding values for stayability at 36, 48, 60, 72 and 84 months of age, calving success and longevity were estimated. The estimated heritabilities on the underlying scale for these traits were $0.06,0.10$, $0.06,0.03,0.11,0.03$ and 0.08 respectively. Product-moment correlations between breeding values for stayability traits were low. The highest correlation of 0.22 was obtained between the ages of 36 and 48 months. Heritability estimates and correlations between traits appear to be of such a low magnitude that selection for these characteristics would result in limited genetic improvement, and also indicate that sires had little influence on the stayability, longevity or calving success of their daughters.
\end{abstract}

Keywords: Beef cattle, longevity, reproduction, threshold analysis, heritability

\# Author to whom correspondence should be addressed. E-mail: sjsc@maties.sun.ac.za

\section{Introduction}

Reproductive fitness is of critical importance for optimum biological and economic efficiency in the beef cattle enterprise. Reproduction is a complex trait with many components. Some of these components, such as calving success, longevity and stayability manifest themselves as threshold traits, while other components such as calving date, calving interval and age at first calving are of a continuous nature. Threshold traits are not continuous in their expression and exhibit distinct categorical phenotypes. The understanding of the inheritance of such traits lies in the visualisation that the trait has an underlying continuity with a threshold, which imposes a discontinuity on the visible expression of the trait (Falconer \& Mackay, 1996). The relationship between polygenes and the expression of discontinuous traits comes about through the establishment of thresholds. Linear model methodology, such as Henderson's method III, has frequently been used for the analysis of discontinuous as well as continuous data (Olivier et al. 1998). This method of analysing discontinuous data with linear procedures is based on continuous phenotypic distributions and does not take the discontinuity of threshold traits into consideration. According to Gianola (1982), the main theoretical objection to using BLUP (best linear unbiased prediction) with categorical data is that breeding values and residuals are not independent of each other. Threshold procedures should therefore be more suitable for analysis of categorical traits such as reproduction and stayability. The objectives of this study were to employ threshold procedures to estimate heritabilities and possible correlations between predicted sire breeding values for stayability at 36, 48, 60, 72 and 84 months of age, longevity and calving success.

\section{Materials and methods}

Data for this study were obtained from the multibreed composite beef cattle herd of the Johannesburg Metropolitan Council, South Africa. The animals were kept on two farms under an intensive management system (Paterson, 1981; MacGregor, 1997). Cows were inseminated during two restricted breeding seasons of approximately three to four months per year. Animals that did not conceive during the SeptemberDecember breeding season were inseminated again during the May-July breeding season. Records of heifers and cows collected from 1974 until 1993 were included in the analysis. Incomplete records and data from animals that calved outside the two calving seasons were removed from the dataset.

During this period 5694 heifers entered the herd. Seventy-six percent of these heifers were not culled at 36 months of age, and 56, 38, 27 and 19\% were still in the herd at 48, 60, 72 and 84 months of age respectively (Fig. 1). 


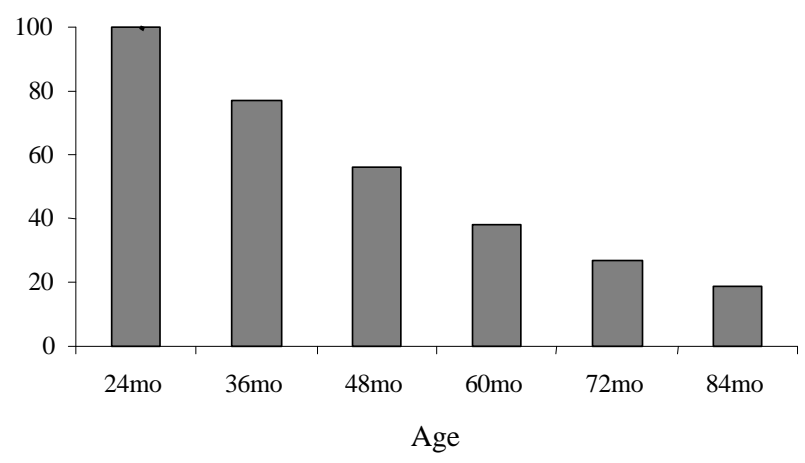

Figure 1 Percentage of dams of various ages that were retained in the herd relative to the number of heifers in the herd at 24 months of age.

Of all females present at 24 months of age, $76 \%$ were retained at 36 months of age, while $24 \%$ were culled (Table 1). The majority were removed due to failure to calve $(22 \%)$. There was no evidence that culling percentage was affected by stayability level, and $20-24 \%$ of females in each opportunity group were culled.

Table 1 Percentage of animals retained and culled at various stayability levels

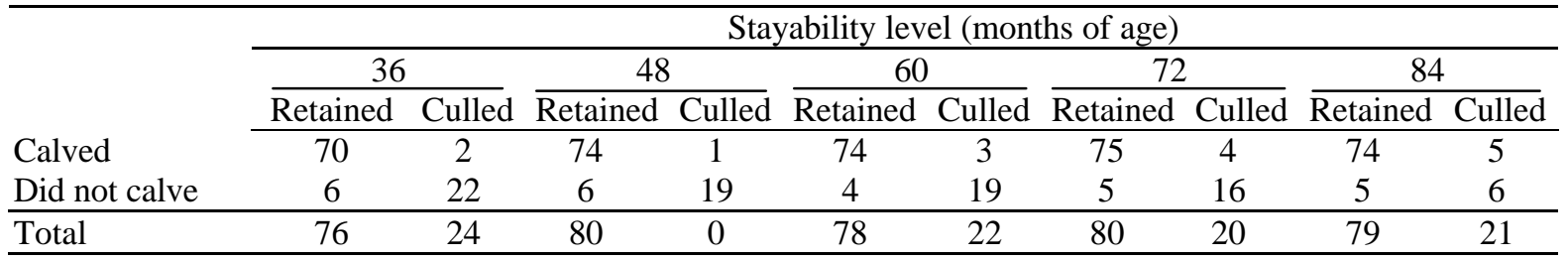

The traits analysed in this study were calving success (CS), stayability at different ages $(36,48,60,72$ and 84 months) and longevity. Stayability was defined as the probability of an animal surviving to a specific age, given the opportunity to reach that age. For analysis of stayability level data were divided into five opportunity groups containing records of only those animals that had the opportunity to survive to $36,48,60$, 72 or 84 months. The records of animals included in the later opportunity groups also appeared in previous opportunity groups since no females were introduced from outside the closed herd. Stayability records were thus coded as " 1 " if the cow survived to the given age, or "0" if it was her last record. Stayability was measured each year for each of the different opportunity groups. Calving success was coded similarly. If a cow calved during a specific year, she was assigned a " 1 ", otherwise a " 0 " was assigned. Longevity was calculated from the age at which the last data-set was recorded, e.g. if the last record for a cow was derived from data for 6 years of age, a longevity record of 6 was assigned. Longevity varied between two and ten years.

The data set included data from 5694 daughters at 36 months of age (Table 2). The number of records decreased with age, and for 84 months of age there were only 1366 daughters of 128 sires still in the herd. During the period of investigation, 5808 daughters of 171 sires were culled or died, and these records were used to estimate longevity.

Table 2 Number of sire and daughter records used for estimation of various trait parameters

\begin{tabular}{lccccccc}
\hline & Calving & \multicolumn{5}{c}{ Stayability level (months of age) } & Longevity \\
\cline { 2 - 7 } & success & 36 & 48 & 60 & 72 & 84 & 171 \\
\cline { 2 - 7 } Number of sires & 254 & 243 & 220 & 178 & 146 & 128 & 5808 \\
Number of daughters & 26177 & 5694 & 3972 & 2775 & 1900 & 1366 & 580 \\
\hline
\end{tabular}


The categorical data modelling (CATMOD) procedure of SAS Institute Inc. (1993) was used to estimate the importance of non-genetic sources of variation. Farm, dam age, calving success (applied only to longevity and to stayability levels), dam birth year and production year were considered as non-genetic sources of variance in the initial model. All non-genetic sources were treated as fixed effects. The number of levels applied in the final model for each fixed non-genetic effect is shown in Table 3. Two models were used for analysis of stayability level as the model became over-specified when both production year and dam birth year were included. Farm, calving success and dam birth year were thus included as fixed effects in one model and farm, calving success and production year were included in the other.

Table 3 Number of levels used for fixed non-genetic effects

\begin{tabular}{|c|c|c|c|c|c|c|c|}
\hline \multirow{2}{*}{$\begin{array}{l}\text { Non-genetic } \\
\text { sources }\end{array}$} & \multirow{2}{*}{$\begin{array}{l}\text { Calving } \\
\text { success }\end{array}$} & \multicolumn{5}{|c|}{ Stayability level (months of age) } & \multirow[b]{2}{*}{ Longevity } \\
\hline & & 36 & 48 & 60 & 72 & 84 & \\
\hline Farm & & 2 & 2 & 2 & 2 & 2 & 2 \\
\hline Dam age & 9 & & & & & & \\
\hline Calving success & & 2 & 2 & 2 & 2 & 2 & 2 \\
\hline Dam birth year & 19 & 19 & 18 & 17 & 15 & 15 & 18 \\
\hline Production year & 19 & 18 & 19 & 18 & 15 & 16 & \\
\hline
\end{tabular}

Since threshold traits are not normally distributed, but expressed in two or more distinct categories, a threshold model was used to estimate heritabilities and to predict breeding values. A set of programmes for the analysis of "mixed" threshold models (GFCAT) based on the principles described by Gianola \& Foulley (1983) and developed by Konstantinov (1995) was used. These non-linear methods are based on the standardised threshold model concept, under which the trait occurs as a result of an underlying unobserved phenotype exceeding a threshold (Konstantinov et al., 1994). The unobserved continuous phenotypes are assumed to be normally distributed. The following model was used:

$$
\mu=\mathrm{X} b+\mathrm{Zs}
$$

where $\mu$ is a vector of underlying means, $b$ is a vector associated with the fixed effects, $s$ is a vector of sire effects and $\mathrm{X}$ and $\mathrm{Z}$ are design matrices. Solutions for thresholds, $b$ and $s$ were computed as described by Konstantinov et al. (1994). Since this is a sire model that requires that the sire variance $\left(\sigma_{\mathrm{s}}{ }^{2}\right)$ be known, a REML-type procedure, as proposed by Harville \& Mee (1984), was used. Heritabilities $\left(\mathrm{h}^{2}\right)$ were estimated as:

$$
h^{2}=\frac{4 \sigma_{s}^{2}}{\left(1+\sigma_{s}^{2}\right)}
$$

Simple product moment correlations between the predicted breeding values of individual sires were estimated for each trait in order to obtain genetic correlations between traits.

\section{Results and Discussion}

Farm, calving success, dam birth year and the year in which the dam had a record for that specific level (production year) influenced stayability at 36, 48, 60, 72 and 84 months of age $(\mathrm{P} \leq 0.01)$. As farm had no effect on calving success $(\mathrm{P}=0.125)$, only dam age, dam birth year and production year were included as fixed effects in the operational model. Farm, calving success and the dam birth year affected longevity $(\mathrm{P} \leq$ $0.01)$ and were therefore included as fixed effects in the operational model.

The percentage of dams retained in the herd is shown in Table 4. In general, a higher percentage of dams were retained on Farm 1 than on Farm 2. Culling was mainly due to failure to calve in the previous year. Dam birth year was included as a non-genetic effect in the operational model because the percentage of dams culled differed between years. As there was a three-year time lag between birth year and production year, the corresponding production and the dam birth year effects displayed the same pattern, the only difference being that of year number. For example, the difference between dam birth year and production year would be three years for 36 months stayability, four years for 48 months stayability and seven years for 84 months stayability. The best production years (the year in which the dams calved), during which the least 
number of females were culled, were 1993, 1993, 1991 and 1993 for 48, 60, 72 and 84 month stayability respectively.

Table 4 Percentage of dams retained in the herd at 36, 48, 60, 72 and 84 months of age for the fixed effects of farm, calving success and for dam birth and production year.

\begin{tabular}{|c|c|c|c|c|c|c|}
\hline \multirow{2}{*}{$\begin{array}{l}\text { Non-genetic } \\
\text { Effect }\end{array}$} & \multirow[b]{2}{*}{ Level } & \multicolumn{5}{|c|}{ Stayability level (months of age) } \\
\hline & & 36 & 48 & 60 & 72 & 84 \\
\hline \multicolumn{7}{|l|}{ Farm } \\
\hline & 1 & 78.37 & 80.87 & 80.54 & 80.88 & 82.07 \\
\hline & 2 & 76.02 & 78.75 & 78.27 & 82.30 & 81.58 \\
\hline \multicolumn{7}{|l|}{ Calving success } \\
\hline & Calve & 98.84 & 98.76 & 97.68 & 97.29 & 95.83 \\
\hline & Did not calve & 22.83 & 22.52 & 19.37 & 22.74 & 28.52 \\
\hline \multicolumn{7}{|l|}{ Dam birth year } \\
\hline & 1973 & 54.86 & 73.74 & 74.07 & 74.47 & 75.86 \\
\hline & 1974 & 85.44 & 69.47 & 85.12 & 68.42 & 79.63 \\
\hline & 1975 & 70.37 & 76.47 & 72.86 & 76.47 & 66.67 \\
\hline & 1976 & 77.14 & 68.94 & 80.91 & 79.31 & 80.56 \\
\hline & 1977 & 73.54 & 78.95 & 75.84 & 78.07 & 70.33 \\
\hline & 1978 & 65.87 & 70.64 & 69.62 & 73.08 & 69.05 \\
\hline & 1979 & 72.33 & 77.69 & 65.59 & 77.01 & 83.33 \\
\hline & 1980 & 64.54 & 67.03 & 71.20 & 82.02 & 84.29 \\
\hline & 1981 & 53.71 & 72.04 & 85.29 & 85.96 & 87.76 \\
\hline & 1982 & 70.11 & 80.00 & 90.20 & 85.26 & 82.72 \\
\hline & 1983 & 80.28 & 83.56 & 83.33 & 81.13 & 88.00 \\
\hline & 1984 & 84.30 & 81.76 & 80.59 & 87.27 & 85.64 \\
\hline & 1985 & 79.35 & 86.36 & 84.59 & 87.28 & 77.38 \\
\hline & 1986 & 81.65 & 86.71 & 83.33 & 80.09 & 90.29 \\
\hline & 1987 & 84.33 & 81.22 & 71.96 & 85.24 & 73.33 \\
\hline & 1988 & 79.18 & 78.51 & 87.72 & 72.73 & \\
\hline & 1989 & 81.10 & 87.53 & 78.26 & & \\
\hline & 1990 & 84.93 & 71.76 & & & \\
\hline & 1991 & 76.06 & & & & \\
\hline \multicolumn{7}{|l|}{ Production year } \\
\hline & 1975 & 43.33 & & & & \\
\hline & 1976 & 63.10 & 61.54 & & & \\
\hline & 1977 & 85.44 & 78.08 & 81.25 & & \\
\hline & 1978 & 70.37 & 69.47 & 71.05 & 61.54 & \\
\hline & 1979 & 77.14 & 76.47 & 85.12 & 79.41 & 77.78 \\
\hline & 1980 & 73.54 & 68.94 & 72.86 & 68.42 & 75.00 \\
\hline & 1981 & 65.87 & 78.95 & 80.91 & 76.47 & 79.63 \\
\hline & 1982 & 72.33 & 70.64 & 75.84 & 79.31 & 66.67 \\
\hline & 1983 & 64.54 & 77.69 & 69.62 & 78.07 & 80.56 \\
\hline & 1984 & 53.71 & 67.03 & 65.59 & 73.08 & 70.33 \\
\hline & 1985 & 70.11 & 72.04 & 71.20 & 77.01 & 69.05 \\
\hline & 1986 & 80.28 & 80.00 & 85.29 & 82.02 & 83.33 \\
\hline & 1987 & 84.30 & 83.56 & 90.20 & 85.96 & 84.29 \\
\hline & 1988 & 79.35 & 81.79 & 83.33 & 85.26 & 87.76 \\
\hline & 1989 & 81.65 & 86.36 & 80.59 & 81.13 & 82.72 \\
\hline & 1990 & 84.33 & 86.71 & 84.59 & 87.27 & 88.00 \\
\hline & 1991 & 79.18 & 81.22 & 83.33 & 87.28 & 85.64 \\
\hline & 1992 & 81.10 & 78.51 & 71.96 & 80.09 & 77.38 \\
\hline & 1993 & 84.93 & 87.53 & 87.72 & 85.24 & 90.29 \\
\hline & 1994 & 76.60 & 71.76 & 78.26 & 72.73 & 73.33 \\
\hline
\end{tabular}


The percentage of dams that calved is shown in figure 2. Cows born in 1985 were the most productive dams with an average of $77 \%$ calvings per opportunity, while those born in 1973 were the least productive with only $61 \%$ calvings per calving opportunity. Of all the cows that were in production in 1975, only $44 \%$ calved, while $78 \%$ of the cows that were in production during 1990 calved.

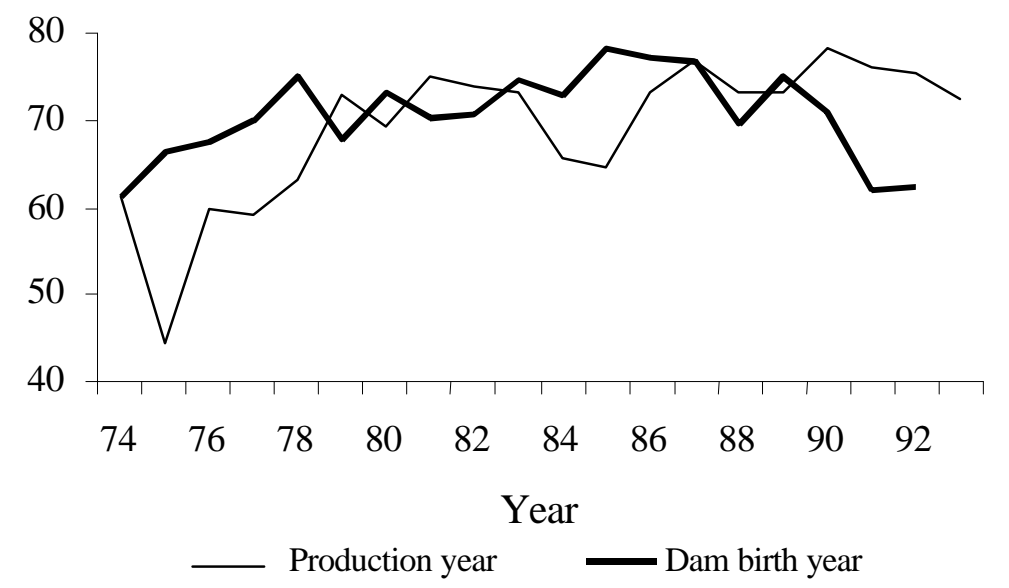

Figure 2 Calving percentage of dams of different dam-birth and production years

Unfortunately, the model became over-specified when both dam birth year and the year the dam had a record for a specific trait (production year) were included. Both effects were, however, significant and are of biological value. It is conceivable that poor reproductive development as a result of a dam birth year that coincided with a period of nutrient scarcity would increase the likelihood of culling at an early age.

Solutions of thresholds, farm, calving success (CS) and dam age are presented in Table 5. Two categories (one threshold) were used for stayability and calving success and ten categories (nine thresholds) for longevity. The thresholds are given as a deviation from the first threshold, which is set to zero. Table 5 shows an increase in the threshold for longevity with a subsequent drop after threshold eight, the threshold between nine and ten years of age. This indicates that a dam's chances of staying in the herd increased with age until nine years, after which it dropped rapidly, probably owing to culling for age. The solutions for farm, calving success and dam age are all deviations from the last category, which is set to zero. Viewed across all stayability levels, animals at Farm 2 had a higher probability of being retained. The solutions for dam age as a fixed effect for calving success varied with no distinct pattern, but eight-year-old dams had a higher probability of giving birth to a calf and two-year-old dams were more likely to fail. The threshold solutions for the dam birth year and production year have no biological value, and are thus not discussed further.

Heritability estimates for each trait are given in Table 6. The heritabilities for the different stayability levels are in close agreement for both models, therefore, only results from model one are discussed. Heritability estimates for stayability were low, and in agreement with Parker et al. (1959), Miller et al. (1967), Schaeffer (1975), Van Doormaal et al. (1986) and Snelling et al. (1995). Hudson \& Van Vleck (1981) obtained estimates of 0.02, 0.04, 0.05, 0,05 and 0.05 at 36, 48, 60, 72 and 84 months, respectively in a Holstein herd. Heritability estimates of the various stayability levels were relatively constant across opportunity groups, except for those of 48 and 84 months stayability $(0.10$ and 0.11 respectively) that were slightly higher than those of the other stayability levels. Miller et al. (1967) also reported heritabilities for herd life that were relatively constant across opportunity groups. However, Everett et al. (1976) and Hudson \& Van Vleck (1981) showed that heritability for stayability level increased with age at which stayability was measured in the interval from 36 to 72 months of age.

The heritability estimate of 0.03 for calving success was low and is in agreement with other reports. Meyer et al. (1990) obtained heritabilities of 0.08, 0.02 and 0.08 for calving success in Herefords, Angus and Zebu crosses respectively, while Mackinnon et al. (1990) reported an average heritability estimate for cow fertility of 0.11 . The heritability of 0.08 for longevity was also low and corresponds with other estimates (Parker et al., 1959; Miller et al. 1967; Hudson \& Van Vleck, 1981). Arguments against active selection pressure for longevity include low heritabilities, the increased generation interval necessary to obtain survival information, and automatic selection because long-lived cows contribute more offspring to subsequent generations than do short-lived cows (Parker et al., 1960; Miller et al., 1967; Nicholson et al., 
1978. However, Van Vleck's (1980) procedure for evaluating sires for stayability may reduced the waiting period for a proof. Bakker et al. (1980) showed that stayability might be important in determining expected net profits from one conception.

Table 5 Solutions for thresholds, farm, calving success and dam age

\begin{tabular}{|c|c|c|c|c|c|c|c|c|c|c|c|c|}
\hline \multicolumn{13}{|c|}{ Stayability (months of age) } \\
\hline & 36 & 36 & 48 & 48 & 60 & 60 & 72 & 72 & 84 & 84 & \multirow{2}{*}{$\begin{array}{l}\text { Calving } \\
\text { Success }\end{array}$} & \multirow[b]{2}{*}{ Longevity } \\
\hline & Model 1 & Model 2 & Model 1 & Model 2 & Model 1 & Model 2 & Model 1 & Model 2 & Model 1 & Model 2 & & \\
\hline \multicolumn{13}{|c|}{ Threshold } \\
\hline 1 & 0.0000 & 0.0000 & 0.0000 & 0.0000 & 0.0000 & 0.0000 & 0.0000 & 0.0000 & 0.0000 & 0.0000 & 0.0000 & 0.0000 \\
\hline 2 & & & & & & & & & & & & 0.5713 \\
\hline 3 & & & & & & & & & & & & 0.9440 \\
\hline 4 & & & & & & & & & & & & 1.2788 \\
\hline 5 & & & & & & & & & & & & 1.5363 \\
\hline 6 & & & & & & & & & & & & 1.7642 \\
\hline 7 & & & & & & & & & & & & 2.0104 \\
\hline 8 & & & & & & & & & & & & 2.2216 \\
\hline 9 & & & & & & & & & & & & 0.2843 \\
\hline \multicolumn{13}{|c|}{ Farm } \\
\hline 1 & -0.3270 & -0.3339 & -0.2406 & -0.2449 & -0.1212 & -0.1282 & -0.1337 & -0.1337 & -0.0239 & -0.0263 & & \\
\hline 2 & 0.0000 & 0.0000 & 0.0000 & 0.0000 & 0.0000 & 0.0000 & 0.0000 & 0.0000 & 0.0000 & 0.0000 & & \\
\hline \multicolumn{13}{|c|}{ CS } \\
\hline 1 & -3.4659 & -3.4641 & -3.2755 & -3.3192 & -2.8833 & -2.9154 & -2.5786 & -2.5786 & -2.3625 & -2.3720 & & 0.7163 \\
\hline 2 & 0.0000 & 0.0000 & 0.0000 & 0.0000 & 0.0000 & 0.0000 & 0.0000 & 0.0000 & 0.0000 & 0.0000 & & 0.0000 \\
\hline \multicolumn{13}{|c|}{ Dam age } \\
\hline 2 & & & & & & & & & & & -0.4573 & \\
\hline 3 & & & & & & & & & & & 0.1249 & \\
\hline 4 & & & & & & & & & & & 0.3587 & \\
\hline 5 & & & & & & & & & & & -0.2710 & \\
\hline 6 & & & & & & & & & & & -0.3649 & \\
\hline 7 & & & & & & & & & & & -0.2948 & \\
\hline 8 & & & & & & & & & & & 0.6426 & \\
\hline 9 & & & & & & & & & & & -0.1837 & \\
\hline 10 & & & & & & & & & & & 0.0000 & \\
\hline
\end{tabular}

Table 6 Heritabilities of reproductive and stayability traits

\begin{tabular}{llc}
\hline Trait & & Heritability $\left(\mathrm{h}^{2}\right)$ \\
\hline Calving Success $(\mathrm{CS})$ & & 0.03 \\
36 month stayability & model 1 & 0.06 \\
& model 2 & 0.04 \\
48 month stayability & model 1 & 0.10 \\
& model 2 & 0.07 \\
60 month stayability & model 1 & 0.06 \\
& model 2 & 0.05 \\
72 month stayability & model 1 & 0.03 \\
\multirow{2}{*}{84 month stayability } & model 2 & 0.03 \\
& model 1 & 0.11 \\
Longevity & model 2 & 0.11 \\
\hline
\end{tabular}

The South African Journal of Animal Science is available online at http://www.sasas.co.za/Sajas.html 
Product-moment correlations between the various levels of stayabilities and calving success are shown in Table 7. These correlations were all low and varied from 0.01 (between 60 and 84 months) to 0.22 (between 48 and 84 months). No correlation of any genetic value could be found. There will be little to no improvement in level of stayability when selection is applied at another level. The same pattern was found for calving success and different stayability levels. This also emphasises the low heritabilities for these traits. In general, these correlations differed from those found in the literature. Hudson \& Van Vleck (1981) reported correlations between stayability levels that varied between 0.72 and 1.00 . They obtained a correlation of 1.00 between stayability at 60 and 72 months, 0.95 between 48 and 72 months, 0.76 between 36 and 60 months, 0.80 between 36 and 48 months, 0.70 between 36 and 72 months and 0.72 between 36 and 60 months. The low product moment correlations found in this study could be due to the inclusion of calving success in the stayability models because the possible variance due to calving success is catered for. In the present study, there were no further records for a cow that was culled at 60 months, but in the study of Hudson \& Van Vleck (1981) such a cow would have received a zero for the 78 and 84 month stayability levels. Thus, in the present study, a dam could receive a series of ones during her lifetime but only one zero, while a dam in the study of Hudson \& Van Vleck (1981) could receive more then one zero. This could be the reason for the large differences between correlations reported here compared to other studies.

Table 7 Product-moment correlations between stayability levels and calving success

\begin{tabular}{lccccc}
\hline & \multicolumn{3}{c}{ Stayability level (months of age) } & Calving \\
\cline { 2 - 5 } $\begin{array}{l}\text { Stayability level } \\
\text { (months of age) }\end{array}$ & 48 & 60 & 72 & 84 & \\
\hline 36 & 0.22 & 0.13 & 0.09 & 0.14 & 0.14 \\
48 & & 0.06 & 0.20 & 0.00 & 0.12 \\
60 & & & 0.19 & 0.01 & 0.04 \\
72 & & & & 0.02 & 0.07 \\
84 & & & & & 0.20 \\
\hline
\end{tabular}

\section{Conclusions}

Provided sufficient genetic variation exists, predictions of genetic merit for stayability may allow selection of sires whose daughters are more likely to remain in the herd. It can also be useful in the selection of replacement heifers. The heritabilities for and correlations between longevity, stayability and calving success estimated from this data appear to be of such a low magnitude that it seems unlikely that these traits could be improved through selection.

\section{Acknowledgement}

The authors are grateful for the use of the data of the Johannesburg Metropolitan Council and thank Roger Wood in particular. The authors also thank the University of the Orange Free State for the use of GFCAT.

\section{References}

Bakker, J.J., Everett, R.W. \& Van Vleck, L.D., 1980. Profitability index for sires. J. Dairy Sci. 63, 1334.

Dalsted, N.L. \& Guiterrez, P.H., 1989. How long do you keep her? BEEF Spring: 15.

Dickerson, G.E., 1970. Efficiency of animal production - molding the biological components. J.Anim. Sci.30, 849.

Dickerson, G.E., 1978. Animal size and efficiency: basic concepts. Anim. Prod. 27, 367.

Doyle, S.P., Golden, B.L., Green, R.D. \& Brinks, J.S., 2000. Additive genetic parameter estimated for heifer pregnancy and subsequent reproduction in Angus females. J.Anim. Sci. 78, 2091.

Essl, A., 1998. Longevity in dairy cattle breeding: a review. Livest. Prod. Sci. 57, 79.

Everett, R.W., Keown, J.F. \& Clapp, E.E., 1976. Production and stayability trends in dairy cattle. J.Dairy Sci. 59, 1532.

Falconer, D.S. \& Mackay, T.F.C., 1996. Introduction to Quantitative Genetics. Longman, New York.

Gianola, D., 1982. Theory and analyses of threshold characters. J. Anim. Sci. 54, 1078.

Gianola, D. \& Foulley, J.L., 1983. Sire evaluation for ordered data with a threshold model. Genet. Sel. Evol. $15,201$. 
Harville, D.A. \& Mee, R.W., 1984. A mixed model procedure for analysing ordered categorical data. Biometrics 40, 393.

Hudson, G.F.S. \& Van Vleck, L.D., 1981. Relationship between production and stayability in Holstein cattle. J. Dairy Sci. 64, 2246.

Koots, K.R., Gibson, J.P. \& Wilton, J.W., 1994. Analyses of published genetic parameters estimates for beef production traits. 1. Heritability. Anim. Breed Abst. 62, 309.

Konstantinov, K.V., Erasmus, G.J. \& van Wyk, J.B., 1994. Evaluation of Dormer sires for litter size and lamb mortality using a threshold model. S. Afr. J. Anim. Sci. 24, 119.

Konstantinov, K.V., 1995. GFCAT: User's Guide. University of the Orange Free State, Bloemfontein.

MacGregor, R.G., 1997. Evaluation of methods of measuring reproduction and production in beef cows. $\mathrm{PhD}$ thesis. University of Pretoria, South Africa.

Mackinnon, M.J., Taylor, J.F. \& Hetzel, D.J.S., 1990. Genetic variation and co-variation in beef cow and bull fertility. J. Anim. Sci. 68, 1208.

Melton, B.E., 1995. Conception to consumption: The economics of genetic improvement. In: Proc. Beef Improvement Federation $27^{\text {th }}$ Research Symposium and Annual Meeting, Sheridan, Wyoming. pp. 40.

Meyer, K., Hammond, K., Parnell, P.F., Mackinnon, M.J. \& Sivarajasingam, S., 1990. Estimates of heritability and repeatability for reproductive traits in Australian beef cattle. Livest. Prod. Sci. 25, 15.

Miller, P., Van Vleck, L.D. \& Henderson, C.R., 1967. Relationships among herd life, milk production and calving interval. J. Dairy Sci., 50, 1283.

Nicholson, H.H., Schaeffer, L.R., Burnside, E.B \& Freeman, M.G., 1978. Use of later records in dairy sire evaluation. Can J. Anim. Sci. 58, 615.

Olivier, W.J., Snyman, M.A., van Wyk, J.B. \& Erasmus, G.J., 1998. Genetic parameter estimates for fitness traits in South African Merino sheep. Livest. Prod. Sci. 56, 71.

Parker J.B., Bayley, N.D., Fohrman, M.H. \& Plowman, R.D., 1959. Factors influencing dairy cattle longevity. J. Dairy Sci. 43, 401.

Paterson, A.G., 1981. Factors affecting post weaning growth and reproduction of crossbred cattle under an intensive production system. D.Sc. (Agric.) thesis. University of Pretoria, South Africa.

SAS Institute Inc., 1993, SAS/STAT Users Guide, Version 6, Vol.1, $4^{\text {th }}$ ed. SAS Institute Inc., Cary, NC. pp. 405.

Schaeffer, L.R., Burnside, E.B \& Freeman, M.G., 1975. Evaluation of Ontario Holstein dairy sires for milk and fat production. J. Dairy Sci. 58, 109.

Snelling, W.M., Golden, B.L. \& Bourdon, R.M., 1995. Within-herd genetic analyses of stayability of beef females. J. Anim. Sci. 73, 993.

Van Doormaal B.J., Burnside, E.B. \& Schaeffer, L.R., 1986. Stayability of Canadian Holsteins. Holstein Journal, June 1986.

Van Vleck, L.D., 1980. Stayability evaluation as a categorical trait and by considering other traits. J. Dairy Sci. 63, 1172. 